\title{
Twelve-minute walking test for assessing disability in chronic bronchitis
}

\author{
C R McGAVIN，S P GUPTA， G J R McHARDY
}

British Medical fournal, 1976, 1, 822-823

\section{Summary}

The distance covered in 12 minutes' walking was used to test exercise tolerance in chronic bronchitis. The distance covered bore a poor relation to the forced expiratory volume in 1 second but a significant relation to the forced vital capacity and the maximum oxygen consumption and ventilation on a bicycle ergometer. The test may be a simple practical guide to everyday disability in chronic bronchitis.

\section{Introduction}

Clinicians commonly judge exercise tolerance in patients with chronic bronchitis on the basis of the clinical history and simple spirometric tests. ${ }^{1}$ Exercise testing in a laboratory is less common. $^{2}$ We have investigated a simple practical test-a measurement of the distance covered in 12 minutes' walkingas a further estimate of exercise tolerance.

A 12-minute test was originally described by Cooper ${ }^{3}$ as a guide to physical fitness. He found a close relation in healthy young men between the distance covered in 12 minutes' running and the maximum oxygen uptake measured on a treadmill and subsequently published tables relating to oxygen consumption, fitness, and 12-minute distance in both sexes over a range of ages. ${ }^{4}$ We describe here our initial experience of a test of this kind in chronic bronchitis, compare the results with other indices of respiratory function, and attempt to evaluate the test as a guide to respiratory disability.

\section{Methods}

The test was carried out in a level enclosed hospital corridor. Each patient was instructed to cover as much ground as he could on foot in 12 minutes. He was told to keep going continuously if possible but not to be concerned if he had to slow down or stop to rest. His aim was to feel at the end of the test that he could not have covered more ground in the time. A doctor accompanied the subject, acting as timekeeper and giving encouragement as necessary.

Other tests-Forced expiratory volume in one second $\left(\mathrm{FEV}_{1}\right)$ and forced vital capacity (FVC) were measured on a low-resistance spirometer, ${ }^{5}$ the best of three readings being taken. ${ }^{6}$ Progressive exercise testing was performed on an electrically braked bicycle ergometer (Elema). The work load was initially $17 \mathrm{~W}(100 \mathrm{kpm} / \mathrm{min})$ for two minutes, increasing thereafter by $17 \mathrm{~W}(100 \mathrm{kpm} / \mathrm{min})$ each minute. Expired gas was collected in a Tissot spirometer during the last half minute of each work load and was analysed for oxygen and carbon dioxide. The values of oxygen uptake and ventilation during the second half minute of the greatest work load which the subject could maintain for one minute were designated $\dot{\mathrm{Vo}}_{2}(\mathrm{ex})$ and $\dot{\mathrm{V}}_{\mathrm{E}}(\mathrm{ex})$.

Patients and procedure-The 35 subjects were men aged 40 to 70 years with chronic bronchitis according to the criteria laid down by the

\footnotetext{
Department of Respiratory Diseases, University of Edinburgh, City Hospital, Edinburgh EH10 5SB

C R MCGAVIN, MRCP, medical registrar

$S$ P GUPTA, MD, Commonwealth fellow

G J R MCHARDY, FRCP, consultant in clinical respiratory physiology
}

Medical Research Council.; Their mean FEV $( \pm$ SD) was $1.05 \pm$ 0.58 litres and mean FVC $2.84 \pm 0.93$ litres at body temperature and pressure, saturated (BTPS). They were tested on at least two days, which were not necessarily consecutive. The order of the tests was always: spirometry, the 12-minute test, and, after a rest of about 20 minutes, the progressive exercise test. The progressive exercise test was performed by only 29 subjects.

\section{Results}

The reproducibility of the 12-minute test was investigated in 12 hospital inpatients who performed it three times on different days. The 12-minute distances ranged from 238 metres to 1463 metres, and the mean distances ( \pm SD) covered on the three days were $891 \pm 286$ metres, $955 \pm 313$ metres, and $996 \pm 336$ metres. Thus the differences $( \pm$ SE of mean) between the mean distances were $64 \pm 21$ metres between days 1 and 2 and $41 \pm 18$ metres between days 2 and 3 . In this group, the mean $\mathrm{FEV}_{1}$ was found to rise from 0.96 litre on day 1 to 1.14 litres on day 3. Analysis of covariance showed that, by allowing for the changing $\mathrm{FEV}_{1}$, the increase in distance travelled on day 2 compared with that travelled on day 1 was significant at the $5^{\circ} \%$ level, but the further increase on day 3 was not significant. A comparison of the results of day 3 with those of day 2 showed that four patients walked less far and eight patients walked further. The mean change ( $\pm \mathrm{SD}$ ), as a percentage of the distance on day 2 , was $+7.33 \pm$ $4 \cdot 22^{\circ} \%$. The range of change was $-6 \cdot 7 \%$ to $+15.3 \%$; the range of the change in metres was -46 metres to +137 metres.

Data from two days' tests were available in more subjects, both inpatients and outpatients. In this group the mean increase in the 12-minute distance on day 2 ( \pm SE of mean) (49 \pm 13.4 metres) was again highly significant (measured in 29 patients; $\mathrm{P}<0.001$ ). But no significant change between the two days occurred in $\mathrm{FEV}_{1}, \mathrm{FVC}$, or maximum work loads achieved on the ergometer (in 29 patients) or $\mathrm{Vo}_{2}$ (ex) (in 26 patients) or the standard values ${ }^{2}$ of ventilation and heart rate at an oxygen consumption of $33.5 \mathrm{mmol} / \mathrm{min}(750 \mathrm{ml} / \mathrm{min})$ (in 22 patients). Because of these findings the results of the tests on the second day were used in the following analysis.

Data from the 35 patients, including the initial 12, were available for correlating 12-minute distance, $\mathrm{FEV}_{1}$, and FVC. Distance walked correlated significantly with FVC $(r=0.406 ; \mathrm{P}<0.05)$ but not with $\mathrm{FEV}_{1}(\mathrm{r}=0.283 ; \mathrm{P}>0.05)$

Twenty-nine patients performed both the 12-minute test and the progressive exercise test. $\mathrm{Vo}_{2}$ (ex) correlated well with $\mathrm{FEV}_{1}$ (r $=$ $0.65 ; \mathrm{P}<0.01)$ and FVC $(r=0.67 ; \mathrm{P}<0.01)$. There were less close, though still significant, relationships between $\dot{\mathrm{Vo}}_{2}(\mathrm{ex})$ and 12 -minute distance $(\mathrm{r}=0.52 ; \mathrm{P}<0.01)$, and between $\dot{\mathrm{V}}_{\mathrm{E}}(\mathrm{ex})$ and 12-minute distance $(r=0.53 ; \mathrm{P}<0.01)$

No ill effects of the walking test were observed apart from some muscular stiffness.

\section{Discussion}

These results suggest that the distance covered in 12 minutes' walking is a reproducible measure of effort tolerance in patients with chronic bronchitis. The test requires no apparatus and is applicable to patients with disease of all grades of severity. The act of walking is familiar to all, while this is less true of exercise on a bicycle ergometer or treadmill. Furthermore, the patient can choose and adjust his own pace throughout the test, pausing for rest if necessary. The use of a standard time rather than a standard distance applies a more uniform test of endurance. Twelve minutes has in other studies been shown to be an appropriate length of time to test oxygen uptake and endurance. ${ }^{8}$

The important increase in distance walked on the second occasion may have been due to practice, although no similar 
improvement occurred in the values of the progressive exercise test. The walking test must be carried out twice, therefore, to achieve reproducible results.

In reviewing the usefulness of measuring the $\mathrm{FEV}_{1}$ in chronic bronchitis, most importantly this has been described as a guide to prognosis. ${ }^{9}$ It also correlates well with the maximum oxygen uptake and ventilation achieved during a progressive exercise test. ${ }^{10}$ The relationships that we found closely match those reviewed by Spiro et al. ${ }^{11}$ The $\mathrm{FEV}_{1}$ and the closely related maximum voluntary ventilation also correlate with effort intolerance as assessed by a questionnaire. ${ }^{12}$ But Gilson and Hugh-Jones ${ }^{12}$ studied coal miners who were not necessarily bronchitics and many of whom had no or minimal symptoms. Capel and Smart ${ }^{1}$ showed a trend of diminishing $\mathrm{FEV}_{1}$ from controls through those with mild and moderate effort intolerance to those with severe effort intolerance due to airways obstruction. Their figures show, however, that at an $\mathrm{FEV}_{1}$ of around 1 litre there is a considerable range of effort intolerance. Confirming this point, our data, based on direct measurement of effort intolerance, showed that there was a striking lack of correlation between $\mathrm{FEV}_{1}$ and 12-minute distance, which emphasises the range of performance found in patients with established airways obstruction.

Performance in tests of the type of the 12-minute walk must depend on various factors, including motivation, endurance, respiratory function, cardiovascular fitness, and neuromuscular function. These are also factors that govern "everyday disability." We suggest that the 12-minute test shares with the respiratory questionnaire the potential to establish everyday disabilityinformation that is not available from measurements of maximal exercise performance. The 12-minute test has the advantage over the questionnaire, however, that it is objective and allows patients to be placed on a continuous scale of performance rather than in arbitrary grades of disability.

Thus, although the $\mathrm{FEV}_{1}$ in chronic bronchitis correlates well with the maximum performance, it does not predict effort intolerance in tests requiring more-prolonged submaximal effort. The reason for this may be that in patients with airways obstruction of this severity the factors limiting performance in tests requiring maximum effort (including $\mathrm{FEV}_{1}$, maximum expiratory flow volume curves, and progressive exercise testing) are the mechanical properties of the airways. ${ }^{13}$ The 12 -minute test and, indeed, most everyday activities do not necessarily take all patients to these limits.

The 12-minute test provides useful objective information about exercise tolerance in chronic bronchitis. We are continuing to explore its use in assessing exercise tolerance in chronic bronchitis and other forms of respiratory disease.

We thank Mrs M Shotter for statistical advice, Miss Sylvia Merchant and the staff of the respiratory laboratory, City Hospital, for technical help, and Mrs M Jack for secretarial help.

\section{References}

1 Capel, L H, and Smart, J, Lancet, 1959, 1, 960

${ }^{2}$ Spiro, S G, et al, Clinical Science and Molecular Medicine, 1974, 46, 191. ${ }^{3}$ Cooper, K H, Fournal of the American Medical Association, 1968, 203, 201. 4 Cooper, K H, The New Aerobics. New York, Evans, 1970.

${ }^{5}$ McKerrow, C B, McDermott, M, and Gilson, J C, Lancet, 1960, 1, 149.

${ }^{6}$ Freedman, S, and Prowse, K, Lancet, 1966, 2, 618.

7 Medical Research Council Working Party, Lancet, 1965, 1, 775.

${ }^{8}$ Katch, F, Ergonomics, 1973, 16, 227.

9 Renzetti, A D, McClement, J H, and Litt, B D, American fournal of Medicine, 1966, 41, 115.

10 Vyas, M N, et al, American Review of Respiratory Disease, 1971, 103, 390.

11 Spiro, S G, et al, Thorax, 1975, 30, 415.

12 Gilson, J C, and Hugh-Jones, P, Lung Function in Coalworkers' Pneumoconiosis, p 133. Medical Research Council, Special Report Series No 290. London, HMSO, 1955.

${ }^{13}$ Leaver, D G, and Pride, N B, Scandinavian fournal of Respiratory Diseases, 1971, suppl 77, p 23.
How are mobile miniature radiography units insulated, what radiation protection is used, and what scatter is there in the vicinity of the van?

The arrangements required for the radiation protection of mass miniature radiographic equipment are governed by the principles that apply to all radiographic procedures, ${ }^{1}$ and responsibility for all radiation protection matters lies with the controlling authority. The scattered radiation dose near the van is influenced by three factors. Firstly, the level of the primary beam is such that its lower edge is a few metres off the ground. Secondly, the dose will be attenuated as the beam passes through the wall of the van. Thirdly, it will fall off rapidly outside the van as it is inversely proportional to the square of the distance. The dose received by a member of the public standing immediately next to the wall of a van for one hour should not exceed one-tenth of the annual dose limit. ${ }^{2}$ ${ }^{1}$ Code of Practice for the Protection of Persons against Ionizing Radiation arising from
Medical and Dental Use, pp 18 and 22 . London, HMSO, 1972 .
${ }^{2}$ Personal communication, National Radiation Protection Board.

Are combined oral contraceptives contraindicated in hyperlidaemia of Frederickson type IIa?

Presumably the answer depends, firstly, on whether the patient has this condition or whether the oral contraceptive caused the hyperlipoproteinaemia in the first place and secondly whether further treatment with an oestrogen-progestogen combination is apt to exacerbate the abnormality. Certainly oral contraceptives can cause a rise in serum cholesterol, ${ }^{1}$ and could therefore be responsible for the xanthelasma and the Frederickson type IIa lipid profile. But oral contraceptives usually have a more severe effect on the serum triglyceride concentration, which are normal in these patients. The rise in triglyceride is related to the dose of the oestrogen ${ }^{2}$ and may be expected to be low with low-dose oral contraceptives. The question is more complicated than appears at first sight. Although attention is usually focused on the oestrogen component of the pill, the pro- gestogen element is not without effect on lipid metabolism. Thus the rise in serum triglyceride concentration is more in women receiving mestranol and chlormadinone acetate than in women given mestranol and norethisterone. ${ }^{3}$ Perhaps if the right combined oral contraceptive is chosen the effect on this patient's lipid profile would be minimal. None of this adds up to an absolute interdict on oral contraceptives for women with a raised serum cholesterol. But this woman is already in a category of increased risk of coronary artery disease. Why add to that risk? I would not unless efficient contraception is imperative for her and there is no other means of dealing with the problem.

${ }^{1}$ Doar, $\mathrm{J} \mathrm{W}$, in Clinics in Endocrinology and Metabolism, 2, No 3, p 505. London, W B Saunders and Co, 1973.

Stokes, T, and Wynn, V, Lancet, 1971, 2, 677. . Endocrinologica, 1970, 63, 717.
Larsson-Cohn, V, Berlin, R, and Vikrot, O, Acta End

A postmenopausal patient living in central Africa has suffered for a year with what appears to be urethritis. The foul-smelling, brown urine grows Döderlein's bacillus in great numbers. What investigation and treatment are advisable?

Döderlein's bacillus is a normal commensal of the vagina. It does not usually smell foul but the smell could be due to other anaerobic organisms from the vagina such as bacteroides and streptococci. The growth of these organisms suggests there is a connection between the urethra or bladder and the vagina. This fistula may be quite small and very difficult to detect. It may be easier to see if a dye such as methylene blue is instilled into the urethra. Milk, which does not stain the tissues yet is readily seen, may also be used. In the absence of a fistula the urine may be becoming contaminated with vaginal organisms during collection. The presence of many vaginal squames in the urine deposit would indicate this. Urine should be examined within an hour or two of collection to eliminate spuriously high bacterial counts due to growth of contaminating organisms in the urine. A careful search should also be made for pathogens in the vagina (trichomonas, candida, etc) and these treated where appropriate. 